\title{
Quality Inspection and Grading of Agricultural and Food Products by Computer Vision- A Review
}

\author{
Narendra V G \\ Sr. Lecturer, Dept. of CSE \\ Manipal Institute of Technology \\ Manipal, Karnataka, India-576 104
}

\begin{abstract}
The paper presents the recent development and application of image analysis and computer vision system in quality evaluation of products in the field of agricultural and food. It is very much essential to through light on basic concepts and technologies associated with computer vision system, a tool used in image analysis and automated sorting and grading is highlighted.
\end{abstract}

In India the ever-increasing population, losses in handling and processing and the increased expectation of food products of high quality and safety standards, there is a need for the growth of accurate, fast and objective quality determination of food and agricultural products. Computer vision is a rapid, economic, consistent and objective inspection technique, which has expanded into many diverse industries. Its speed and accuracy satisfy everincreasing production and quality requirements, hence aiding in the development of totally automated processes. This non-destructive method of inspection has found applications in the agricultural and food industry, including the inspection of quality and grading of fruit and vegetable. It has also been used successfully in the analysis of grain characteristics and in the evaluation of foods such as potato chips, meats, cheese and pizza. This paper reviews the progress of computer vision in the agricultural and food field then explores different possible areas of research having a wider scope to enhance the existing algorithms to meet the today's challenges.

Keywords: Quality; Grading and Sorting; Computer vision System; Agricultural and Food Products; Image analysis and Processing;

\section{INTRODUCTION}

Technological advancement is gradually finding its applications in the field of agricultural and food, in response to one of the greatest challenges i.e. meeting the need of the growing population. Efforts are being geared up towards the replacement of human operator with automated systems, as human operations are inconsistent and less efficient. Automation means every action that is needed to control a process at optimum efficiency as controlled by a system that operates using instructions that have been programmed into it or response to some activities. Automated systems in most cases are faster and more precise. However, there are some basic infrastructures that must 
necessarily be in place in automation. Computer vision is a relatively young discipline with its origin traced back to the 1960s[5]. Following an explosion of interest during the 1970s, it has experienced continued growth both in Research and Development. Sonka et al. [70] reported that more than 1000 papers are published each year in the expanding fields of computer vision and image processing. Applications of these techniques have expanded to various areas such as medical diagnostic, automatic manufacturing and surveillance, remote sensing, technical diagnostics, autonomous vehicle and robot guidance.

Computer vision is the construction of explicit and meaningful descriptions of physical objects from images [2]. Timmermans[80] states that it encloses the capturing, processing and analysis of two-dimensional images, with others noting that it aims to duplicate the effect of human vision by electronically perceiving and understanding an image [70]. The basic principle of computer vision is described in Fig. 1. Image processing and image analysis are the core of computer vision with numerous algorithms and methods available to achieve the required classification and measurements [27].

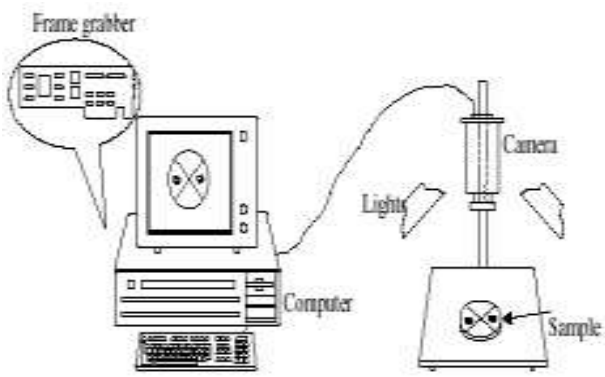

Figure 1: Components Of A Computer Vision System [87].
Computer vision systems have been used increasingly in the food and agricultural areas for quality inspection and evaluation purposes as they provide suitably rapid, economic, consistent and objective assessment [73]. They have proved to be successful for the objective measurement and assessment of several agricultural products [80]. Over the past decade advances in hardware and software for digital image processing have motivated several studies on the development of these systems to evaluate the quality of diverse and processed foods [35,12]. Computer vision has been recognized as a potential technique for the guidance or control of agricultural and food processes [77]. Therefore, over the past 25 years, extensive studies have been carried out, thus generating many publications.

The majority of these studies focused on the application of computer vision to product quality inspection and grading. Traditionally, quality inspection of agricultural and food products has been performed by human graders. However, in most cases these manual inspections are time-consuming and labourintensive. Moreover the accuracy of the tests cannot be guaranteed [55]. By contrast it has been found that computer vision inspection of food products, was more consistent, efficient and cost effective [37];[75]. Also, with the advantages of superior speed and accuracy, computer vision has attracted a significant amount of research aimed at replacing human inspection. Recent research has highlighted the possible application of vision systems in other areas of agriculture, including the analysis of animal behavior [66], applications in the implementation of precision farming and machine guidance [79], forestry [27] and plant feature measurement and growth analysis [89]. 
Besides the progress in research, there is increasing evidence of computer vision systems being adopted at commercial level. This is indicated by the sales of ASME (Application Specific Machine Vision) systems into the North American food market, which reached 65 million dollars in 1995 [35]. Gunasekaran [15] reported that the food industry is now ranked among the top ten industries using machine vision technology. This paper reviews the latest development of computer vision technology with respect to quality inspection in the agricultural and food fields.

\section{ASSESSMENT OF FRUITS AND NUTS}

Computer vision has been widely used for the quality inspection and grading of fruits and vegetables. It offers the potential to automate manual grading practices and thus to standardize techniques and eliminate tedious inspection tasks. Kanali et al. [24] reported that the automated inspection of produce using machine vision not only results in labour savings, but can also improve quality inspection objectivity.

\subsection{Apples}

The study of apples using computer vision has attracted much interest and can reflect the progress of computer vision technology for fruit inspection. Computer vision has been used for such tasks as shape classification, defects detection, quality grading and variety classification. Paulus and Schrevens [57] developed an image-processing algorithm based on Fourier expansion to characterize objectively the apple shape so as to identify different phenotypes. In this research it was shown that four images per apple were needed to quantify the average shape of a randomly chosen apple. It was found that this profile analysis can be used to characterize existing shape descriptor lists, e.g. of ideal apples as defined by the International Board for Plant Genetic Resources. Hence it links existing subjective shape descriptors and objective measurements of shape recognition. Experimentation by Paulus et al. [58] also used Fourier analysis of apple peripheries as a quality inspection/classification technique. This methodology gave insight into the way in which external product features affect the human perception of quality. The research found that as the classification involved more product properties and became more complex, the error of human classification increased.

Leemans [28] investigated the defect segmentation of 'Golden Delicious' apples using machine vision. To segment the defects, each pixel of an apple image was compared with a global model of healthy fruits by making use of the Mahalanobis distances. The proposed algorithm was found to be effective in detecting various defects such as bruises, russet, scab, fungi or wounds. In similar studies Yang [94] assessed the feasibility of using computer vision for the identification of apple stems and calyxes which required automatic grading and coring. Back propagation neural networks were used to classify each patch as stem/calyx or patch-like blemish. An overall accuracy of $95 \%$ was reported for the 69 Golden Delicious and 55 Granny Smith samples examined. Earlier studies proposed the use of a 'flooding' algorithm to segment patch-like defects (russet patch, bruise, and also stalk or calyx area) [93]. It was found that this method of feature identification is applicable to other types of produce with uniform skin colour. This technique was improved by Yang and Marchant 
[95], who applied a 'snake' algorithm to closely surround the defects. To discriminate russet in 'Golden Delicious' apples a global approach was used and the mean hue on the apples was computed [20]. A discriminants function sorted the apple as accepted or rejected. The accuracy reached $82.5 \%$, which is poor compared with European standards [20]. Other studies involving 'Golden Delicious' apples were performed for the purpose of classification into yellow or green groups using the HSI (hue, saturation, intensity) colour system method [75]. The results show that an accuracy of over 90\% was achieved for the 120 samples tested.

Steinmetz et al. [72] investigated sensor fusion for the purpose of sugar content prediction in apples by combining image analysis and nearinfrared spectrophotometic sensors. The repeatability of the classification technique was improved when the two sensors were combined giving a value of $78 \%$ for the 72 test samples. An online system with the use of a robotic device resulted in a running time of $3.5 \mathrm{~s}$ per fruit for the technique [44].

\subsection{Oranges}

Computer vision has been applied to the classification of oranges by reference to their visual characteristics. Ruiz et al. [64] studied three image analysis methods to solve the problem of long stems attached to mechanically harvested oranges. The techniques include colour segmentation based on linear discriminants analysis, contour curvature analysis and a thinning process, which involves iterating until the stem becomes a skeleton. It was found that these techniques were able to determine the presence or absence of a stem with certainty; however, stem location was correctly estimated in 93,90 and $98 \%$ for the different techniques, respectively, in the samples tested. A study by Kondo [25] investigated the quality evaluation, i.e. by the correlation of appearance with sweetness, of Iyokan oranges using image processing so as to automate the orange classification operation. The results demonstrated that the method could effectively predict the sweetness of the oranges with a $87 \%$ correlation efficiency between measured and calculated sugar content obtained from neural networks.

\subsection{Strawberries}

Strawberry appearance and fruit quality are dependent on a number of pre- and postharvest factors, hence variation occurs, necessitating the need for sorting. Nagata et al. [47] investigated the use of computer vision to sort fresh strawberries, based on size and shape. The experimental results show that the developed system was able to sort the 600 strawberries tested with an accuracy of $94-98 \%$ into three grades based on shape and five grades on size. Another automatic strawberry sorting system was developed by Bato et al.,[4]. Average shape and size accuracies of 98 and $100 \%$, respectively, were obtained regardless of the fruit orientation angle with judgement time within $1.18 \mathrm{~s}$.

\subsection{Oil Palm Fruits}

The current practice in the oil palm mills is to grade the oil palm bunches manually using human graders. This method is subjective and subject to disputes. Meftah Sallem M et. al., [42] developed an automated grading system for oil palm bunches using the RGB colour model. This grading system was developed to distinguish between the three different categories of oil palm fruit bunches. The 
maturity or colour-ripening index based on different colour intensity. The colours namely Red, Green and Blue of the palm oil fruit bunch were investigated using this grading system. The result showed that the ripeness of fruit bunch could be differentiated between different categories of fruit bunches based on RGB intensity.

\subsection{Papayas}

Prior to export, papayas are subjected to inspection for the purpose of quality control and grading. For size grading, the fruit is weighted manually hence the practice is tedious, time consuming and labour intensive. Therefore, a computer vision system for papaya size grading using shape characteristic analysis. The shape characteristics consisting of area, mean diameter and perimeter were extracted from the papaya images. Slamet Riyadi et al., [68] classified according to combinations of the three features to study the uniqueness of the extracted features. The proposed technique showed the ability to perform papaya size classification with more than $94 \%$ accuracy.

\subsection{Kiwifruits}

Fruit Shape is one of the most important quality parameters for evaluation by customer's preference. Additionally, misshaped fruits are generally rejected according to sorting standards of fruit. This Majid Rashidi et al., [39] was carried out to determine quantitative classification of algorithm for fruit shape in kiwifruit (Actinidia deliciosa). Physical attributes of kiwifruit such as outer dimensions, mass, volume, and density were measured. The result of the study indicated that aspect ratio could be used effectively to determine normal and misshapen fruit.

\subsection{Nuts}

Mixing of pistachio nuts of different varieties and quality often occurs as a result of mixed plantations or during harvesting and handling, hence separation and classification must be performed. For the detection of early split lesions on the hull of pistachio nuts machine vision has been used [60]. The developed system classified early split nuts with $100 \%$ success and normal nuts with $99 \%$ accuracy out of a total of 180 nuts tested. In other research a multi-structure neural network (MSNN) classifier was proposed and applied to classify four varieties (classes) of pistachio nuts [13]. In this study, the performance of the MSNN classifier was compared with the performance of a multiplayer feed-forward neural network (MLNN) classifier. The average accuracy of the MSNN classifier was $95.9 \%$, an increase of over $8.9 \%$ of the performance of the MLNN, for the four commercial varieties of nuts tested with 150 samples in each. An automated machine vision system was developed to identify and remove pistachio nuts with closed shells from processing streams [59]. The system included a novel material handling system to feed nuts to line scan cameras without tumbling. The classification accuracy of this machine vision system for separating open shell from closed shell nuts was approximately $95 \%$, similar to mechanical devices. The system has a throughput rate of approximately 40 nuts per $s$ comparable to colour sorters used to remove other pistachio defects.

\subsection{Tomatoes}

Tomato quality is primarily based on uniform shape and freedom from growth and handling defects. Nielsen et al. [53] developed a technique to correlate the attributes of size, 
colour, shape and abnormalities, obtained from tomato images, with the inner quality of the tomato samples. They applied fuzzy sets into their study. Recently, chaos theory was introduced into this area [45]. In this study tomato fruit shape was quantitatively evaluated using an attractor, fractal dimension and neural networks. The results showed that a combination of these three elements offers more reliable and more sophisticated classification. Computer vision has also been used in the assessment of tomato seedling quality as a classification technique to ensure only good quality seedlings were transplanted [31]. The classification process adopted an adaptive thresholding technique, the Oust method. The disagreement between canopy areas measured by manual examination and machine vision segmented, canopy portion boundaries, had a range from -2.6 to $+2.3 \%$.

\subsection{Peaches and Pears}

As consumer awareness and sophistication increases the importance of objective measurement of quality is ever increasing. In a study by Miller and Delwiche [43] the maturity of market peaches was evaluated by colour analysis. Their method was based on comparing peach ground colour with reference peach maturity colour to estimate the amount of blushed surface area. However, an accuracy of only $54 \%$ agreement with manual classification was achieved for the 160 peaches examined. This inaccuracy was a result of only two views of the peaches captured, i.e. some of surface not imaged and also because of errors in manual grading. A more recent study by Dewulf et al., [9] combined image processing with a finite element model to determine the firmness of pears. The application of computer vision technology to detect pear bruising was studied by Zhang and Deng [100]. Results from the experiments confirmed that different bruised areas could be precisely detected with most relative errors controlled to within $10 \%$.

\subsection{Pomegranate}

The pomegranate is a fruit with excellent organoleptic and nutritional properties, but the fact that it is difficult to peel affects its commercialization and decreases its potential consumption. One solution is to market the arils of pomegranate in a ready-to-eat form. However, after the peeling process, unwanted material, such as internal membranes and defective arils, is extracted together with good arils and must be removed on the packing line because the presence of such material shortens the shelf life of the product or deteriorates its appearance. For different reasons, the commercial sorting machines that are currently available for similar commodities (cherries, nuts, rice, etc.) are not capable of handling and sorting pomegranate arils, thus making it necessary to build specific equipment. This work of J. Blasco et al., [22] describes the development of a computer vision-based machine to inspect the raw material coming from the extraction process and classifies it in four categories. The machine is capable of detecting and removing unwanted material and sorting the arils by colour. The prototype is composed of three units, which are designed to 
singulate the objects to allow them be inspected individually and sorted. The inspection unit

relies on a computer vision system. Two image segmentation methods were tested: one uses a

threshold on the $\mathrm{R} / \mathrm{G}$ ratio and the other is a more complex approach based on Bayesian Linear Discriminant Analysis (LDA) in the RGB space. Both methods offered an average success rate of $90 \%$ on a validation set, the former being more intuitive for the operators, as well as faster and easier to implement, and for these reasons it was included in the prototype. Subsequently, the complete machine was tested in industry by working in real conditions throughout a whole pomegranate season, in which it automatically sorted more than nine tons of arils.

\subsection{Fruit harvesting}

The automatic location of fruit in a harvesting scene is of added interest with developments in robotics and improvements in mechanized harvesting. The feasibility of using computer vision for this purpose was determined by $\mathrm{Pla}$ et al., [61]. To locate the fruit, the regions from a segmented image labeled as fruit colour were taken as the fruit position in the image. In tests of 19 images $95 \%$ of visible fruits were detected and a $6 \%$ failure rate. A vision algorithm for the guidance of a robotic cherry tomato harvester was developed by Kondo et al., [26]. This visual feedback control based harvesting method achieved a success rate of $70 \%$ for the 62 fruits attempted.
Table 1: Summary of Fruits and Nuts

\begin{tabular}{|c|c|c|c|}
\hline Product & Application & $\begin{array}{l}\text { Reported } \\
\text { Accuracy }\end{array}$ & Ref. \\
\hline Apples & $\begin{array}{l}\text { Defects } \\
\text { detection } \\
\text { Grading } \\
\text { Classification }\end{array}$ & $\begin{array}{c}--- \\
95 \% \\
78 \%\end{array}$ & $\begin{array}{l}{[57]} \\
{[93]} \\
{[72]}\end{array}$ \\
\hline Oranges & $\begin{array}{l}\text { Classification } \\
\text { Quality } \\
\text { Evaluation }\end{array}$ & $93 \%$ & $\begin{array}{c}{[64]} \\
{[25]}\end{array}$ \\
\hline Strawberries & Sorting & $94-98 \%$ & [47] \\
\hline $\begin{array}{l}\text { Oil Palm } \\
\text { Fruits }\end{array}$ & Sorting & --- & {$[42]$} \\
\hline Papayas & Classification & $94 \%$ & {$[68]$} \\
\hline Nuts & Classification & $95 \%$ & [59] \\
\hline Pomegranate & $\begin{array}{l}\text { Sorting } \\
\text { (Arils) }\end{array}$ & $90 \%$ & {$[22]$} \\
\hline
\end{tabular}

\section{VEGETABLE INSPECTION}

\subsection{Mushrooms}

Computer vision has been shown to be a viable approach to inspection and grading of vegetables [67]. Heinemann et al., [19] assessed the quality features of the common white Agaricus bisporus mushroom using image analysis in order to inspect and grade the 
mushrooms by an automated system. Of the 25 samples examined misclassification by the vision system ranged from 8 to $56 \%$ depending upon the quality feature evaluated, but averaged about 20\%. The study also reported that disagreement between human inspectors ranged from 14 to $36 \%$. Reed et al. [62] found that computer vision could be combined with harvester technology to select and pick mushrooms based on size. Computer vision has also been applied to objective measurement of the developmental stage of mushrooms [82]. This study found that cap opening of mushrooms correlated the best with the stage of development except for tightly closed mushrooms. Other research described the development of computer vision techniques for the detection, selection, and tracking of mushrooms prior to harvest [90].

From the spectral analyses on the colour of different mushroom diseases Vi'zha'nyo' and Tillett [83] concluded that the colour of the developed, senescent mushroom differs from any browning caused by diseases allowing earlier detection of infected specimens. Similar research developed a method, involving a series of complex colour operations, to distinguish the diseased regions of mushrooms from naturally senescing mushrooms [84]. Intensity normalization and image transformation techniques were applied in order to enhance colour differences in true-colour images of diseased mushrooms. The method identified all of the diseased spots as 'diseased' and none of the healthy, senescent mushroom parts were detected as 'diseased'.

\subsection{Potatoes}

Potatoes have many possible shapes, which need to be graded for sale into uniform classes for different markets. This created difficulties for shape separation. A Fourier analysis based shape separation method for grading of potatoes using machine vision for automated inspection was developed by Tao et al., [76]. A shape separator based on harmonics of the transform was defined. Its accuracy of separation was $89 \%$ for 120 potato samples, in agreement with manual grading. Earlier, Lefebvre et al., [29] studied the use of computer vision for locating the position of pulp extraction automatically for the purpose of further analysis on the extracted sample. An image acquisition system was also constructed for mounting on a sweet potato harvester for the purpose of yield and grade monitoring [91]. It was found that culls were differentiated from saleable sweet potatoes with classification rates as high as $84 \%$.

\subsection{Chilli}

Chilli is a variety grown extensively consumed by almost all the population. It has a high processing demand and proper sorting is required before filling or canning. A sorter that, Federico Hahn [10] classifies chilli by three different width sizes was built. The conveyor used baby suckers to align each chilli during sensing. Chilli width was determined by means of a photodiode scanner, which detected the incoming radiation sent by a laser line generator. Chilies presenting necrosis were detected with a radiometer and removed to increase product quality. Horizontal and vertical widths were measured for 200 chilies. The accuracy on the necrosis detection and width classification was of 96.3 and $87 \%$, respectively. On-line necrosis measurements were $85 \%$ accurate when only the relative reflectance at $550 \mathrm{~nm}$ was used. 


\subsection{Lemons}

Vegetable quality is frequently referred to size, shape, mass, firmness, colour and bruises from which fruits can be classified and sorted. However, technological by small and middle producers implementation to assess this quality is unfeasible, due to high costs of software, equipment as well as operational costs. Based on these considerations, the research is to evaluate a new open software that enables the classification system by recognizing fruit shape, volume, colour and possibly bruises at a unique glance. The software named ImageJ, compatible with Windows, Linux and MAC/OS, is quite popular in medical research and practices, and offers algorithms to obtain the above-mentioned parameters. The software allows calculation of volume, area, averages, border detection, image improvement and morphological operations in a variety of image archive formats [1].

Table 2: Summary of vegetables

\begin{tabular}{|l|l|c|c|}
\hline Product & $\begin{array}{l}\text { Applicati } \\
\text { on }\end{array}$ & $\begin{array}{l}\text { Reported } \\
\text { Accuracy }\end{array}$ & Ref. \\
\hline Potatoes & $\begin{array}{l}\text { Classifica } \\
\text { tion }\end{array}$ & $84 \%$ & {$[91]$} \\
\hline Chilli & $\begin{array}{l}\text { Classifica } \\
\text { tion }\end{array}$ & $\begin{array}{c}87 \& \\
96.3 \%\end{array}$ & {$[10]$} \\
\hline Lemons & $\begin{array}{l}\text { Classifica } \\
\text { tion \& } \\
\text { Sorting }\end{array}$ & ---- & {$[1]$} \\
\hline
\end{tabular}

\subsection{Others}

Some other earlier studies of computer vision associated with vegetable grading and inspection include colour and defect sorting of bell peppers [67]. Morrow et al., [46] presented the techniques of vision inspection of mushrooms, apples and potatoes for size, shape and colour. The use of computer vision for the location of stem/root joint in carrot has also been assessed [3]. Feature extraction and pattern recognition techniques were developed by Howarth and Searcy [21] to characterize and classify carrots for forking, surface defects, curvature and brokenness. The rate of misclassification was reported to be below $15 \%$ for the 250 samples examined. More recently sweet onions were line scanned for internal defects using X-ray imaging [81]. An overall accuracy of $90 \%$ was achieved when spatial and transform features were evaluated for product classification.

\section{GRAIN CLASSIFICATION AND QUALITY EVALUATION}

\subsection{Wheat}

Grain quality attributes are very important for all users and especially the milling and baking industries. Computer vision has been used in grain quality inspection for many years. An early study by Zayas et al.,[98] used machine vision to identify different varieties of wheat and to discriminate wheat from non-wheat components. In later research Zayas et al., [99] found that wheat classification methods could be improved by combining morphometry (computer vision analysis) and hardness analysis. Hard and soft recognition rates of $94 \%$ were achieved for the seventeen varieties examined. Twenty-three morphological features were used for the discriminant analysis of different cereal grains using machine vision [40]. Classification accuracies of 98, 91, 97,100 and $91 \%$ were recorded for CWRS (Canada Western Red Spring) wheat, CWAD (Canada 
Western Amber Durum) wheat, barley, oats and rye, respectively. 25 kernels per image were captured from a total of 6000 for each grain type examined.

The relationship between colour and texture features of wheat samples to scab infection rate was studied using a neural network method [63]. It was found that the infection rates estimated by the system followed the actual ones with a correlation coefficient of 0.97 with human panel assessment and maximum and mean absolute errors of 5 and $2 \%$, respectively. In this study machine vision-neural network based technique proved superior to the human panel. Image analysis has also been used to classify dockage components for CWRS (Canada Western Red Spring) wheat and other cereals [48]. Morphology, colour and morphology-/colour models were evaluated for classifying the dockage components. Mean accuracies of 89 and $96 \%$ for the morphology model and 71 and $75 \%$ for the colour model were achieved when tested on the test and training data sets, respectively. Overall 6000 kernels for each grain type were analyzed. Machine vision was used to identify weeds commonly found in wheat fields in experimentation by Zhang and Chaisattapagon [100]. Five shape parameters were used in leaf shape studies and were found effective in distinguishing broadleaf weed species such as pigweed, thistle and kochia from wheat.

\subsection{Corn}

In order to preserve corn quality it is important to obtain physical properties and assess mechanical damage so as to design optimum handling and storage equipment. Measurements of kernel length, width and projected area independent of kernel orientation have been performed using machine vision [51]. The algorithm accuracy was between 0.86 and 0.89 measured by the correlation coefficient between predicted results and actual sieving for a $500 \mathrm{~g}$ sample. The processing time of the size-grading program was reported as being between 0.66 and $0.74 \mathrm{~s}$ per kernel. Steenhoek and Precetti [71] performed a study to evaluate the concept of two-dimensional image analysis for classification of maize kernels according to size category. A total of 320 maize kernels were categorized into one of 16 size categories based on degree of roundness and flatness. Classification accuracy of both machine vision and screen systems was above $96 \%$ for roundhole analysis. However, sizing accuracy for flatness was less than $80 \%$. $\mathrm{Ng}$ et al., [49] developed a machine vision algorithm for corn kernel mechanical and mould damage measurement, which demonstrated a standard deviation less than $5 \%$ of the mean value of the 250 grains examined. They found that this method was more consistent than other methods available. The automatic inspection of 600 corn kernels was also performed by $\mathrm{Ni}$ et al., [52] using machine vision. For whole and broken kernel identification on-line tests had successful classification rates of 91 and $94 \%$ for whole and broken kernels, respectively.

The whiteness of corn has been measured by an on-line computer vision approach by Liu and Paulsen [32]. For the 63 samples (50-/80 kernels per sample) tested the technique was found to be easy to perform with a speed of 3 kernels per s. In other studies Xie and Paulsen [92] used machine vision to detect and quantify tetrazolium staining in corn kernels. The tetrazolium-machine vision algorithm was used to predict heat damage in corn due to drying air temperature and initial moisture content. 


\subsection{Rice}

As rice is one of the leading food crops of the world its quality evaluation is of importance to ensure it remains appealing to consumers. Liu et al., [33] developed a digital image analysis method for measuring the degree of milling of rice. They compared the method with conventional chemical analysis and obtained a coefficient of determination of $\mathrm{R}^{2}=/ 0.9819$ for the 680 samples tested. Wan et al., [85] employed three online classification methods for rice quality inspection:-namely range selection, neural network and hybrid algorithms. The highest recorded online classification accuracy was around $91 \%$ at a rate of over $1200 \mathrm{kernels} / \mathrm{min}$. The range selection method achieved this accuracy but required time-consuming and complicated adjustment. In another study, milled rice from a laboratory mill and a commercial-scale mill was evaluated for head rice yield and percentage whole kernels, using a shaker table and a machine-vision system called the GrainCheck [34].

\subsection{Lentils}

Colour and appearance of lentils are important grading factors. A machine vision system for colour grading of lentils was developed [38], using a flatbed scanner as the image gathering device. Grain samples belonging to different grades of large green lentils were scanned and analyzed over a two-crop season period. Image colour, colour distribution, and textural features were found to be good indicators of lentil grade. Linear discriminant analysis, k-nearest neighbors, and neural network based classifiers performed equally well in predicting sample grade. An online classification system was developed with a neural classifier that achieved an overall accuracy (agreement with the grain inspectors) of more than $90 \%$.

Table 3: Summary of computer applications for the cereal industry

\begin{tabular}{|l|l|c|c|}
\hline Product & Application & $\begin{array}{c}\text { Reported } \\
\text { Accuracy }\end{array}$ & Ref. \\
\hline Wheat & $\begin{array}{l}\text { Classifiacatio } \\
\text { n of types } \\
\text { Weed } \\
\text { identification }\end{array}$ & $94 \%$ & {$[99]$} \\
\hline Corn & Size & --- & {$[100]$} \\
\hline $\begin{array}{l}\text { Whiteness } \\
\text { barley, } \\
\text { oats, rye }\end{array}$ & Classification & ---- & {$[92]$} \\
\hline Rhole and & $93-90 \%$ & {$[52]$} \\
\hline broken kernel & $91 \& 94 \%$ & {$[51,52]$} \\
\hline Grading & $80-96 \%$ & {$[71]$} \\
\hline Grading & $91 \%$ & {$[85]$} \\
\hline
\end{tabular}

\section{APPLICATIONS IN OTHER FOOD PRODUCTS}

\subsection{Pizza}

Visual features such as colour and size indicate the quality of many prepared consumer foods. Sun [73] investigated this in research on pizza in which pizza topping percentage and 
distribution were extracted from pizza images. Combining three algorithms used to segment many different types of pizzas as the traditional segmentation techniques were found to be inadequate for this application developed a new segmentation algorithm. It was found that the new region-based segmentation technique could effectively group pixels of the same topping together. As the result, topping exposure percentage can be easily determined. The study reported that the accuracy of measuring the topping percentage by the new algorithm reached $90 \%$.

\subsection{Bakery products}

Human perception based on visual inspection has long been recognized as a guide to quality assessment hence if the product fails to meet the customer's preconceptions the possibility of a purchase is greatly diminished. Consequently computer vision has been used in the assessment of confectionery products. Davidson et al., [8] measured the physical features of chocolate chip biscuits, including size, shape baked dough colour, and fraction of top surface area that was chocolate chip using image analysis. Four fuzzy models were developed to predict consumer ratings based on three of the features. A prototype-automated system for visual inspection of muffins was developed by Zaid Abdullah et al., [97]. The colour of 100 light brown and 100 dark brown muffins was evaluated using the vision system and discriminants analysis compared with visual examination. The automated system was able to correctly classify $96 \%$ of pregraded and $79 \%$ of ungraded muffins. The algorithm procedure classified muffins to an accuracy of greater than $88 \%$, compared with $20-30 \%$ variations in quality decisions amongst inspectors. Machine vision has also been used in the assessment of quality of crumb grain in bread and cake products [65]. Using this technique, analyses on the different characteristics influencing the crumb grain were studied.

\subsection{Cheese}

The evaluation of the functional properties of cheese is assessed to ensure the necessary quality is achieved, especially for specialized applications such as consumer food toppings or ingredients. Wang and Sun [86] developed a computer vision method to evaluate the melting and browning of cheese. This novel non-contact method was employed to analyze the characteristics of cheddar and mozzarella cheeses during cooking and the results showed that the method provided an objective and easy approach for analyzing cheese functional properties [87,88]. Ni and Gunasekaran [50] developed an image-processing algorithm to recognize individual cheese shred and automatically measure the shred length. It was found that the algorithm recognized shreds well, even when they were overlapping. It was also reported that the shred length measurement errors were as low as $0.2 \%$ with a high of $10 \%$ in the worst case.

\subsection{Potato Chips}

The images of commercial potato chips were evaluated for various colour and textural features to characterize and classify the appearance and to model the quality preferences of a group of consumers. Features derived from the image texture contained better information than colour features to discriminate both the quality categories of chips and consumers' preferences. Entropy of $a^{*}$ and $V$ and energy of $b^{*}$ from images of the total chip surface, average and variance of $H$ and correlation of $V$ 
from the images of spots and/or defects (if they are present), and average of $L^{*}$ from clean images (chips free of spots and/or defects) showed the best correspondence with the four proposed appearance quality groups (A: 'pale chips', B: 'slightly dark chips', C: 'chips with brown spots', and D: 'chips with natural defects'), giving classification rates of $95.8 \%$ for training data and $90 \%$ for validation data when linear discriminant analysis (LDA) was used as a selection criterion. The inclusion of independent colour and textural features from images of brown spots and/or defects and their clean regions of chips improved the resolution of the classification model and in particular to predict 'chips with natural defects'. Consumers' preferences showed that in spite of the 'moderate' agreement among raters (Kappavalue $=0.51$ ), textural features have potential to model consumer behavior in the respect of visual preferences of potato chips. A stepwise logistic regression model was able to explain $86.2 \%$ of the preferences variability when classified into acceptable and non-acceptable chips [11].

\subsection{Lamb Meat}

The correct assessment of meat quality (i.e., to fulfill the consumer's needs) is crucial element within the meat industry. Although there are several factors that affect the perception of taste, tenderness is considered the most important characteristic. Paulo Corteza et al., [56] presented, a feature selection procedure, based on a Sensitivity Analysis, is combined with a Support Vector Machine, in order to predict lamb meat tenderness. This real-world problem is defined in terms of two difficult regression tasks, by modeling objective (e.g. Warner-Bratzler Shear force) and subjective (e.g. human taste panel) measurements. In both cases, the proposed solution is competitive when compared with other neural (e.g. Multilayer Perceptron) and Multiple Regression approaches.

\subsection{Meat and Meat Products}

Visually discernible characteristics are routinely used in the quality assessment of meat. McDonald and Chen [41] pioneered early work in the area of image based beef grading. Based on reflectance characteristics, they discriminated between fat and lean in the Longisimus muscle and generated binary muscle images. In a more recent study Gerrard et al., [12] examined the degrees of marbling and colour in 60 steaks. The results showed that image processing effectively predicted the lean colour $\left(\mathrm{R}_{2}=0.86\right)$ and marbling scores $\left(\mathrm{R}_{2}=0.84\right)$. Image texture analysis has also been used in the assessment of beef tenderness [30]. Statistic regression and neural network were performed to compare the image features and sensory scores for beef tenderness and it was found that the texture features considerably contributed to the beef tenderness.

Evaluation of pork quality has also been investigated $[37,36]$. The findings indicated that for $93 \%$ of the 44 pork loin samples, prediction error was lower than 0.6 in neural network modeling, hence it is recommended as an effective tool for evaluating fresh pork colour from these studies.

Gray-scale intensity, Fourier power spectrum, and fractal analyses were used as a basis for separating tumorous, bruised and skin torn chicken carcasses from normal carcasses [55]. A neural network classifier used performed with $91 \%$ accuracy for the required separation based on spectral images scanned at both 542 
and $700 \mathrm{~nm}$ wavelengths. In a further study Park and Chen [54] found that a linear discriminant model was able to identify unwholesome chicken carcasses with classification accuracy of $95.6 \%$ while a quadratic model (97\% accuracy) was better to identify wholesome carcasses for the 176 carcasses examined. Earlier Daley et al., [7] analyzed chicken carcasses for systemic defects at a speed of 180 birds per min using global colour histograms based on a neural network classifier. The use of an X-ray inspection system for the detection of bones in chicken and fish was examined by Graves [23]. This system called the 'Bonescan' exploits the fact that the absorption of coefficients of two materials are similar at high energies and so combine images obtained at high and low energies to differentiate bone from meat. The system with a throughput of 10,000 fillets per $\mathrm{h}$ was found to correctly identify remaining bones at an accuracy of $99 \%$, while the fraction of chicked breasts or thighs that it incorrectly rejects is less than $3 \%$ [23].

\subsection{Others}

The focus of a study by Gunasekaran [14] was to develop a computer vision based multi index active food shape feature extractor to minimum errors resulting from position and scaling. A statistical model based (SMB) feature extractor and a multi-index active model (MAM) based feature extractor were tested in conjunction with a multi-index classifier and a minimum intermediate zone (MIZ) classifier were used the extract the desired features from corn kernels, almonds and animal shaped crackers. The results showed that accuracy and speed were greatly improved when the MAM based feature extractor was used with the MIZ classifier. Yin and Panigrahi [96] studied the internal texture of French fries using image techniques. Three computer vision algorithms were used to evaluate the hollowness with a resulting classification accuracy of $100 \%$ achieved.

A study by Locht et al., [35] examined the development of full colour machine vision analysis in the food industry. This WinGrain system analyzed sirloin steak for fat content, chives for rust fungus, meat, pasta and rich dishes for component percentage composition and findings indicated that the system provides objective and quantifiable in-line visual information.

The application of automated image analysis in the beverage industry was described by Braggins [6]. Computer vision was employed for the checking of wrap around sleeves on bottles, inspection of bottled champagne and beer keg inspection.

\section{3-D TECHNIQUE}

In general, only 2-dimensional (2D) data are needed for grading, classification, and analysis of most agricultural images. However, in many applications 3-dimensional image analysis maybe needed as information on structure or added detail is required. A 3-D vision technique has been developed to derive a geometric description from a series of 2-D images [70]. In practice this technique might be useful for food inspection. For example, when studying the shape features of a piece of bakery, it is necessary to take 2-D images vertically and horizontally to obtain its roundness and thickness, respectively. 
Recently Kanali et al., [24] investigated the feasibility of using a charge simulation method (CSM) algorithm to process primary image features for three dimensional shape recognition. The required features were transferred to a retina model identical to the prototype artificial retina and were compressed using the CSM by computing output signals at work cells located in the retina. An overall classification rate of $94 \%$ was obtained when the prototype artificial retina discriminated between distinct shapes of oranges for the 100 data sets tested. Gunasekaran and Ding [18] obtained 3-D images of fat globules in cheddar cheese from 2-D images. This enabled the in situ 3-D evaluation of fat globule characteristics so as the process parameters and fat levels may be changed to achieve the required textural qualities.

\section{ADVANTAGES AND DISADVANTAGES}

The capabilities of digital image analysis technology to generate precise descriptive data on pictorial information have contributed to its more widespread and increased use [65]. Quality control in combination with the increasing automation in all fields of production has led to the increased demand for automatic and objective evaluation of different products. Sistler [69] confirm that computer vision meets these criteria and states that the technique provides a quick and objective means for measuring visual features of products. In agreement it found that a computer vision system with an automatic handling mechanism could perform inspections objectively and reduce tedious human involvement [46]. Human grader inspection and grading of produce is often a labour intensive, tedious, repetitive and subjective task [55]. In addition to its costs, this method is variable and decisions are not always consistent between inspectors or from day to day $[75,19]$. In contrast $\mathrm{Lu}$ et al., [37] found computer vision inspection of food products to be consistent, efficient and cost effective. Hence computer vision has been used widely in agricultural and horticulture to automate many labour intensive process [16]. Even in 1993 Gunasekaran and Ding [17] agreed that machine vision was becoming increasingly popular in the food industry, and pointed out that its development was at a level where it is a robust and competitively priced sensing technique. Yin and Panigrahi [96] noted that cost effectiveness of computer vision technology for the food industry applications is constantly improving.

Computer vision is seen as an easy and quick way to acquire data that would be otherwise difficult to obtain manually [29]. Gerrard et al., [12] recognized that machine image technology provides a rapid, alternative means for measuring quality consistently. Another benefit of machine vision systems is the nondestructive and undisturbing manner in which information is attained [99], making inspection unique with the potential to assist humans involving visually intensive work [76]. Tarbell and Reid [77] noted that an attractive feature of a machine vision system is that it can be used to create a permanent record of any measurement at any point in time. Hence archived images can be recalled to look at attributes that were missed or previously not of interest.

An ambiguity of computer vision is that its results are influenced by the quality of the captured images. Often due to the unstructured nature of typical agricultural settings and biological variation of plants within them, object identification in these applications is 
considerably more difficult. Also if the research or operation in being conducted in dim or night conditions artificial lighting is needed.

\section{CONCLUSIONS}

The paper reviews the recent developments in computer vision for the agricultural and food industry. Computer vision systems have been used increasingly in industry for inspection and quality evaluation purposes as they can provide rapid, economic, hygienic, consistent and objective assessment. However, difficulties still exist, evident from the relatively slow commercial uptake of computer vision technology in all sectors. Even though adequately efficient and accurate algorithms have been produced, processing speeds still fail to meet modern manufacturing requirements. With few exceptions, research in this field has dealt with trials on a laboratory scales thus the area of mechatronics has been neglected, and hence it needs more focused and detailed study.

The adaptation of computer vision for quality evaluation of processed foods, fruits and vegetables is the area for the greatest potential uptake of this technology, as analysis can be based on a standard requirement in already automated controlled conditions. More complex systems are needed for the automated grading of fresh produce because of the greater range in variability of quality and also as produce orientation may influence results. With the idea of precision and more environmental friendly agriculture becoming more realistic the potential for computer vision in this area is immense with the need in field crop monitoring, assessment and guidance systems. However, techniques such as 3D and colour vision will ensure computer vision development continues to meet the accuracy and quality requirements needed in this highly competitive and changing industry.

\section{REFERENCES}

[1].Antonio Carlos Loureiro Lino; Juliana Sanches; Inacio Maria Dal Fabbro, "Image processing techniques for lemons and tomatoes classification", Journal of Food and Engineering, 83(4), pp. 433-440, 2008.

[2].Ballard, D.A., Brown, C.M.,. "Computer Vision", Prentice-Hall, Eaglewoood Cliffs, NJ, 1982.

[3].Batchelor, M.M., Searcy, S.W., "Computer vision determination of stem/root joint on processing carrots.", Journal of Agricultural Engineering Research 43, pp. 259-269, 1989.

[4].Bato, P.M., Nagata, M., Cao, Q.X., Hiyoshi, K., Kitahara, T., "Study on sorting system for strawberry using machine vision (part 2): development of sorting system with direction and judgement functions for strawberry (Akihime variety)", Journal of the Japanese Society of Agricultural Machinery, 62(2), pp. 101-110, 2000.

[5].Baxes, G.A.,'Digital Image Processing Principles and Applications", Wiley, New York, USA 1994.

[6].Braggins, D., "How 'machine vision' can help drinks production", Brewing and Distilling International, 31(5), pp. 16-17, 2000.

[7].Daley, W., Carey, R., Thomson, C., "Realtime colour grading and defect detection of food products", Optics in agriculture, forestry and biological processing SPIE. The International Society of Optical Engineering 2345, pp. 403411, 1994.

[8].Davidson, V.J., Ryks, J., Chu, T., "Fuzzy models to predict consumer ratings for biscuits 
based on digital features", IEEE Transactions on Fuzzy Systems, 9(1), pp. 62-67, 2001.

[9].Dewulf, W., Jancsok, P., Nicolai, B., De Roeck, G., Briassoulis, D., "Determining the firmness of a pear using finite element model analysis", Journal of Agricultural Engineering Research, 74 (3), pp. 217-224, 1999.

[10].Federico Hahn,"Automatic Jalapeno Chilli Grading by Width", Biosystems Engineering, 83(4), pp. 433-440, 2002.

[11].Fermando Mendoza, Petr Dejmek and Jose M Agullera, "Colour and image texture analysis in classification of commercial of commercial potato chips", Food Research International Vol. 40(9), pp. 1146-1154, 2007.

[12].Gerrard, D.E., Gao, X., Tan, J., "Beef marbling and colour score determination by image processing ", Journal of Food Science, 61(1), pp. 145-148, 1996.

[13].Ghazanfari, A., Irudayaraj, J., Kusalik, A.,"Grading pistachio nuts using a neural network approach" Transactions of the ASAE, 39(6), pp. 2319-2324, 1996.

[14].Gunasekaran, D.K., "Shape feature extraction and classification of food material using computer vision", Transactions of the ASAE, 37(5), pp. 1537-1545, 1994.

[15].Gunasekaran, S., “Computer vision technology for food quality assurance", Trends in Food Science and Technology, 7(8), pp. 245-256, 1996.

[16].Gunasekaran, S., "Non-destructive Food Evaluation Techniques to Analyze Properties and Quality", Food Science and Technology
Series. Marcel Dekker, New York, pp. 105, 2001.

[17].Gunasekaran, S., Ding, K., "Using computer vision for food quality evaluation", Food Technology 6, pp. 151-154, 1993.

[18].Gunasekaran, S., Ding, K., "Threedimensional characteristics of fat globules in cheddar cheese", Journal of Dairy Science 82, pp.1890-1896, 1999.

[19].Heinemann, P.H., Hughes, R., Morrow, C.T., Sommer, H.J., Beelman, R.B., Wuest, P.J., "Grading of mushrooms using a machine vision system", Transactions of the ASAE, 37(5), pp. 1671-1677, 1994.

[20].Heinemann, P.H., Varghese, Z.A., Morrow, C.T., Sommer, H.J., III, Crassweller, R.M., "Machine vision inspection of Golden Delicious apples", Applied Engineering in Agriculture Transactions of the ASAE, 11 (6), pp. 901-906, 1995.

[21].Howarth, M.S., Searcy, S.W., "Inspection of fresh carrots by machine vision", In: Food Processing Automation II Proceedings of the 1992 Conference. ASAE, 2950 Niles Road, St. Joseph, MI 4, pp. 9085- 9659, USA, 1992.

[22].J. Blasco, S. Cubero, J. Gómez-Sanchís, P. Mira, E. Moltó, "Development of a machine for the automatic sorting of pomegranate (Punica granatum) arils based on computer vision", Journal of Food Engineering, 90, pp. 27-34, 2009.

[23].Jamieson, V., "Physics reises food standards", Physics World, 1, pp. 21-22, 2002.

[24].Kanali, C., Murase, H., Honami, N., "Three-dimensional shape recognition using a 
chargesimulation method to process image features", Journal of Agricultural Engineering Research, 70, pp. 195-208, 1998.

[25].Kondo, N., "Quality evaluation of orange fruit using neural networks", In: Food Processing Automation IV Proceedings of the FPAC Conference. ASAE, 2950 Niles Road, St. Joseph, MI 4 9085-9659, USA, 1995.

[26].Kondo, N., Nishitsuji, Y., Ling, P.P., Ting, K.C., "Visual feedback guided robotic cherry tomato harvesting", Transactions of the ASAE, 39(6), pp. 2331-2338, 1996.

[27].Krutz, G.W., Gibson, H.G., Cassens, D.L., Zhang, M., "Colour vision in forest and wood engineering", Landwards, 55, pp. 2-9, 2000.

[28].Leemans, V., Magein, H., Destain, M.F., "Defects segmentation on 'Golden Delicious' apples by using colour machine vision", Computers and Electronics in Agriculture 20, pp. 117-130, 1998.

[29].Lefebvre, M., Gil, S., Brunet, D., Natonek, E., Baur, C., Gugeril, P., Pun, T., "Computer vision and agricultural robotics for disease control: the potato operation", Computers and Electronics in Agriculture 9, pp. 85-102, 1993.

[30].Li, J., Tan, J., Martz, F.A., "Predicting beef tenderness from image texture features", In: 1997 ASAE Annual International Meeting Technical Papers, Paper No. 973124, ASAE, 2950 Niles Road, St. Joseph, MI 49085-9659, USA, 1997.

[31].Ling, P.P., Ruzhitsky, V.N., "Machine vision techniques for measuring the canopy of tomato seedling", Journal of Agricultural Engineering Research, 65, pp. 85 -95, 1996.
[32].Liu, J., Paulsen, M.R., "Corn whiteness measurement and classification using machine vision”, In:1997 ASAE Annual International Meeting, Technical Papers, Paper No. 973045, ASAE, 2950 Niles Road, St. Joseph, MI 490859659, USA, 1997.

[33].Liu, W., Tao, Y., Siebenmorgen, T.J., Chen, H., "Digital image analysis method for rapid measurement of rice degree of milling", In: 1997 ASAE Annual International Meeting Technical Papers, Paper No. 973028, ASAE, 2950 Niles Road, St. Joseph, MI 49085-9659, USA, 1997.

[34].Lloyd, B.J., Cnossen, A.G., Siebenmorgen, T.J., "Evaluation of two methods for separating head rice from brokens for head rice yield determination", In: 2000 ASAE Annual International Meeting, Paper No. 006074 ASAE, 2950 Niles Road, St. Joseph, MI 490859659, USA, 2000.

[35].Locht, P., Thomsen, K., Mikkelsen, P., "Full colour image analysis as a tool for quality control and process development in the food industry", Paper No. 973006, ASAE, 2950 Niles Road, St. Joseph, MI 49085-9659, USA, 1997.

[36].Lu, J., Tan, J., Gerrard, D.E., "Pork quality evaluation by image processing", In: 1997 ASAE Annual International Meeting Technical Papers, Paper No. 973125, ASAE, 2950 Niles Road, St. Joseph, MI 49085-9659, USA, 1997.

[37].Lu, J., Tan, J., Shatadal, P., Gerrard, D.E., "Evaluation of pork colour by using computer vision”, Meat Science 56, pp. 57-60, 2000.

[38].M.A. Shahin and S.J. Symons, "A machine vision system for grading lentils", Canadian Biosystems engineering Vol. 432001. 
[39].Majid Rashidi and Keyvan Seyfi, "Classification of Fruit Shape in Kiwifruit Applying the Analysis of Outer Dimensions", International Journal of Agriculture and Biology 1560-8530/09-5-759-762, 2007.

[40].Majumdar, S., Jayas, D.S., Bulley, N.R., "Classification of cereal grains using machine vision, part 1: Morphological features", In: 1997 ASAE Annual International Meeting Technical Papers, Paper No. 973101, ASAE, 2950 Niles Road, St. Joseph, MI 49085-9659, USA, 1997.

[41].McDonald, T., Chen, Y.R., "Separating connected muscle tissues in images of beef carcass rib eyes", Transactions of the ASAE, 33(6), pp. 2059-2065, 1990.

[42].Meftah Salem M Alfantni, Abdul Rashid Mohamed shariff, Helmi Zulhaidi Mohd Shafri, Osama M Ben Saaed and Omar M Eshanta, "Oil Palm Fruit Bunch Grading System Using Red, Green and Blue Digital Number", Journal of Applied Sciences 8(8), pp. 1444 -1452, 2008.

[43].Miller, M.K., Delwiche, M.J., "A colour vision system for peach grading", Transaction of the ASAE, 32 (4), pp. 1484 -1490. 1989.

[44].Molto, E., Blasco, J., Steinmetz, V., Bourley, A., Navarron, F., Pertotto, G., "A robotics solution for automatic handling, inspection and packing of fruits and vegetables", Proceedings of the International Workshop on Robotics and Automated Machinery for Bio-productions. BioRobotics'97, Grandia, Valencia, Spain, 1997.

[45].Morimoto, T., Takeuchi, T., Miyata, H., Hashimoto, Y., "Pattern recognition of fruit shape based on the concept of chaos and neural networks", Computers and Electronics in Agriculture, 26, 171-186, 2000.

[46].Morrow, C.T., Heinemann, P.H., Sommer, H.J., Tao, Y., Varghese, Z., "Automate inspection of potatoes, apples, and mushrooms", In Proceedings of the International Advanced Robotics Programme, Avignon, France, pp. 179-188, 1990.

[47].Nagata, M., Cao, Q., Bato, P.M., Shrestha, B.P., Kinoshita, O., "Basic study on strawberry sorting system in Japan", In: 1997 ASAE Annual International Meeting Technical Papers, Paper No. 973095, ASAE, 2950 Niles Road, St. Joseph, Michigan 49085-9659, USA,1997.

[48].Nair, M., Jayas, D.S., Bulley, N.R., "Dockage identification in wheat using machine vision", 1997 ASAE Annual International Meeting Technical Papers, Paper No. 973043, ASAE, 2950 Niles Road, St. Joseph, Michigan 49085-9659, USA,1997.

[49].Ng, H.F., Wilcke, W.F., Morey, R.V., Lang, J.P., "Machine vision evaluation of corn kernel mechanical and mould damage", In: 1997 ASAE Annual International Meeting Technical Papers, Paper No. 973047, ASAE, 2950 Niles Road, St. Joseph, Michigan 4 90859659, USA, 1997.

[50].Ni, H., Gunasekaran, S., "A computer vision system for determining quality of cheese shreds", In: Food Processing Automation IV Proceedings of the FPAC Conference. ASAE, 2950 Niles Road, St. Joseph, Michigan 490859659, USA, 1995.

[51].Ni, B., Paulsen, M.R., Reid, J.F., "Size grading of corn kernels with machine vision", In: 1997 ASAE Annual International Meeting 
Technical Papers, Paper No. 973046, ASAE, 2950 Niles Road, St.Joseph, Michigan 490859659, USA, 1997a.

[52].Ni, B., Paulsen, M.R., Liao, K., Reid, J.F., "Design of an automated corn kernel inspection system for machine vision", Transactions of the ASAE, 40(2), pp. 491-497, 1997b.

[53].Nielsen, H.M., Paul, W., Munack, A., Tantau, H.J., "Modelling image processing parameters and consumer aspects for tomato quality grading", In: Mathematical and Control Application in Agriculture and Horticulture, Proceedings of the Third IFAC Workshop, Pergamon/Elsevier, Oxford, UK, 1998.

[54].Park, B., Chen, Y.R., "Co-occurrence matrix texture features of multi spectral images on poultry carcasses", Journal of Agricultural Engineering Research, 78(2), pp. 127-139, 2001.

[55].Park, B., Chen, Y.R., Nguyen, M., Hwang, H., "Characterising multispectral images of tumorous, bruised, skin-torn, and wholesome poultry carcasses", Transactions of the ASAE, 39(5), pp. 1933-1941, 1996.

[56].Paulo Cortez, Manuel Portelinha, "Lamb Meat Quality Assessment by Support Vector Machines", Neural Processing Letters, Springer, In press, ISSN:1370-4621, 2006.

[57].Paulus, I., Schrevens, E., “ Shape characterization of new apple cultivars by Fourier expansion of digital images", Journal of Agricultural Engineering Research, 72, pp. 113-11, 1999.

[58].Paulus, I., De Busschers, R, Schrevens, E., "Use of image analysis to investigate human quality classification of apples", Journal of
Agricultural Engineering Research, 68, pp. 341-353, 1997.

[59].Pearson, T., Toyofuku, N., "Automated sorting of pistachio nuts with closed shells", Applied Engineering in Agriculture, 16(1), pp. 91-94, 2000.

[60].Pearson, T.C., Slaughter, D.C., "Machine vision detection of early split pistachio nuts", Transactions of the ASAE, 39(3), pp. 12031207, 1996.

[61].Pla, F., Juste, F., Ferri, F., Vicens, M., "Colour segmentation based on a light reflection model to locate citrus fruits for robotic harvesting", Computers and Electronics in Agriculture, 9, pp. 53-70, 1993.

[62].Reed, J.N., Crook, S., He, W., "Harvesting mushrooms by robot", In: Elliott, T.J. (Ed.), Science and Cultivation of Edible Fung,. Balkema, Rotterdam, pp. 385-391, 1995.

[63].Ruan, R., Ning, S., Ning, A., Jones, R., Chen, P.L., "Estimation of scabby wheat incident rate using machine vision and neural network", In: 1997 ASAE Annual International Meeting Technical Papers, Paper No. 973042, ASAE, 2950 Niles Road, St. Joseph, MI 490859659, USA, 1997.

[64].Ruiz, L.A., Molto, E., Juste, F., Pla, F., Valiente, R., "Location and characterization of the stem calyx area on oranges by computer vision", Journal of Agricultural Engineering Research, 64, pp. 165-172, 1996.

[65].Sapirstein, H.D., "Quality control in commercial baking: Machine vision inspection of crumb grain in bread and cake products", In: Food Processing Automation IV Proceedings of the FPAC Conference, ASAE, 2950 Niles 
Road, St. Joseph, Michigan 49085-9659, USA, 1995.

[66].Sergeant, D., Boyle, R., Forbes, M., "Computer visual tracking of poultry", Computers and Electronics in Agriculture, 21, pp. 1-18, 1998.

[67].Shearer, S.A., Payne, F.A., "Colour and defect sorting of bell peppers using machine vision", Transactions of the ASAE, 33 (6), pp. 2045-2050, 1990.

[68].Slamet Riyadi, Ashrani A. Abd, Rahni Mohd, Marzuki Mustafa, and Aini Hussain, Member, "Shape Characteristics Analysis for Papaya Size Classification", The $5^{\text {th }}$ Student Conference on Research and DevelopmentSCOReD 2007.

[69].Sistler, F.E., "Machine vision techniques for grading and sorting agricultural products", Postharvest News and Information, 2(2), pp. 81-84, 1991.

[70].Sonka, M, Hlavac, V, Boyle, R., "Image Processing, Analysis, and Machine Vision", PWS publishing, California, USA, 1999.

[71].Steenhoek, L., Precetti, C., "Vision sizing of seed corn", In: 2000 ASAE Annual International Meeting, Paper No. 003095 ASAE, 2950 Niles Road, St. Joseph, MI 490859659, USA, 2000.

[72].Steinmetz, V., Roger, J.M., Molto, E., Blasco, J., "On-line fusion of colour camera and spectrophotometer for sugar content prediction of apples", Journal of Agricultural Engineering Research, 73, pp. 207-216, 1999.

[73].Sun, D.-W., "Inspecting pizza topping percentage and distribution by a computer vision method", Journal of Food Engineering, 44, pp. 245-249, 2000.

[74].Tadhg Brosnan, Da-Wen Sun, "Inspection and grading of agricultural and food products by computer vision systems-/a review", Computers and Electronics in Agriculture, 36, pp. 193-213, 2002.

[75].Tao, Y., Heinemann, P.H., Varghese, Z., Morrow, C.T., Sommer, H.J., "III, Machine vision for colour inspection of potatoes and apples", Transactions of the ASAE, 38(5), pp. 1555-1561, 1995a.

[76].Tao, Y., Morrow, C.T., Heinemann, P.H., Sommer, H.J., "Fourier based separation techniques for shape grading of potatoes using machine vision", Transactions of the ASAE, 38(3), pp. 949-957, 1995 b.

[77].Tarbell, K.A., Reid, J.F., "A computer vision system for characterizing corn growth and development", Transactions of the ASAE, 34(5), pp. 2245-2249, 1991.

[78].Tillett, R.D., "Image analysis for agricultural processes", Division Note DN 1585, Silsoe Research Institute, 1990.

[79].Tillett, N.D., Hague, T., "Computer vision based hoe guidance for cereals-an initial trial", Journal of Agricultural Engineering Research, 74, pp. 225-236, 1999.

[80].Timmermans, A.J.M., "Computer vision system for on-line sorting of pot plants based on learning techniques", Acta Horticulture, 421, pp. 91-98, 1998.

[81].Tollner, E.W., Shahin, M.A., Maw, B.W., Gilaitis, R.D., Summer, D.R., "Classification of onions based on internal defects using imaging 
processing and neural network techniques", In: 1999 ASEA International Meeting, Toronto, Onteroi, Paper no. 993165, ASAF, 2950 Niles Road, St. Joseph, MI 49085-9659, USA, 1999.

[82].Van Loon, P.C.C., "Het bepalen van het ontwikkelingsstadium bij dechampignon met computer beeldanalyse", Champignoncultuur, 40(9), pp. 347-353, 1996.

[83].V1'zha'nyo' , T., Tillett, R.D., “Analysis of mushroom spectral characteristics", Proceedings of AgEng'98 International Conference on Agricultural Engineering, Oslo, pp. 24-27, Paper No. 98-F08019981-7, August 1998.

[84].V1'zha'nyo' , T., Felfoldi, J., "Enhancing colour differences in images of diseased mushrooms", Computers and Electronics in Agriculture, 26, pp. 187-198, 2000.

[85].Wan, Y.N., Lin, C.M., Chiou, J.F., "Adaptive classification method for an automatic grain quality inspection system using machine vision and neural network", In: 2000 ASAE Annual International Meeting, Paper No. 003094 ASAE, 2950 Niles Road, St. Joseph, MI 49085-9659, USA, 2000.

[86].Wang, H.-H., Sun, D.-W., "Evaluation of the functional properties of cheddar cheese using a computer vision method", Journal of Food Engineering, 49(1), pp. 47-51, 2001.

[87].Wang, H.-H., Sun, D.-W., "Melting characteristics of cheese: analysis of effects of cooking conditions using computer vision techniques", Journal of Food Engineering, 52(3), pp. 279-284, 2002a.

[88].Wang, H.-H., Sun, D.-W., "Correlation between cheese meltability determined with a computer vision method and with Arnott and Schreiber", Journal of Food Science, 67(2), pp. 745-749, 2002b.

[89].Warren, D.E., "Image analysis research at NIAB: chrysanthemum leaf shape", Plant Varieties and Seeds 10, pp. 59-61, 1997.

[90].Williams, A.L., Heinemann, P.H., "Detection, tracking, and selection of mushrooms for harvest using image analysis", In ASAE Annual International Meeting, Orlando, FL, USA, pp. 12-16, ASAE Paper no. 983041, July 1998.

[91].Wooten, J.R., White, J.G., Thomasson, J.A., Thompson, P.G., "Yield and quality monitor for sweet potato with machine vision", In: 2000 ASAE Annual International Meeting, Paper No. 001123, ASAE, 2950 Niles Road, St. Joseph, MI 49085-9659, USA, 2000.

[92].Xie, W., Paulsen, M.R., "Machine vision detection of tetrazolium in corn", In: 1997 ASAE Annual International Meeting Technical Papers, Paper No. 973044, ASAE, 2950 Niles Road, St. Joseph, MI 49085-9659, USA, 1997.

[93].Yang, Q., “An approach to apple surface feature detection by machine vision", Computers and Electronics in Agriculture 11, pp. 249-264, 1994.

[94].Yang, Q., “Apple stem and calyx identification with machine vision", Journal of Agricultural Engineering Research 63, pp. 229236, 1996.

[95].Yang, Q., Marchant, J.A., “Accurate blemish detection with active contour models", Computers and Electronics in Agriculture 14, pp. 77-89, 1995. 
[96].Yin, H., Panigrahi, S., "Image processing techniques for internal texture evaluation of French fries", In: 1997 ASAE Annual International Meeting Technical Papers, Paper No. 973127, ASAE, 2950 Niles Road, St. Joseph, MI 49085-9659, USA, 1997.

[97].Zaid Abdullah, M., Abdul Aziz, S., DosMohamed, AM., "Quality inspection of bakery products using a colour-based machine vision system", Journal of Food Quality, 23(1), pp. 39-50, 2000.

[98].Zayas, I., Pomeranz, Y., Lai, F.S., "Discrimination of wheat and nonwheat components in grain samples by image analysis", Cereal Chemistry, 66(3), pp. 233237, 1989.
[99].Zayas, I.Y., Martin, C.R., Steele, J.L., Katsevich, A., "Wheat classification using image analysis and crush force parameters", Transactions of the ASAE 39 (6), pp. 21992204, 1996.

[100].Zhang, N., Chaisattapagon, C., "Effective criteria for weed identification in wheat fields using machine vision", Transactions of the ASAE, 38(3), 965-974, 1995.

[101].Zhang, T., Deng, J.Z., “Application of computer vision to detection bruising on pears", Transactions of the Chinese Society of Agricultural Engineering, 15(1), pp. 205-209, 1999. 